OPEN ACCESS

Edited and reviewed by:

Dake Xu,

Northeastern University, China

*Correspondence:

Hongwei Liu

liuhw35@mail.sysu.edu.cn

Tingyue Gu

gu@ohio.edu

Hongfang Liu

liuhf@hust.edu.cn

Specialty section:

This article was submitted to Microbiological Chemistry and

Geomicrobiology,

a section of the journal

Frontiers in Microbiology

Received: 20 June 2019 Accepted: 03 July 2019

Published: 17 July 2019

Citation:

Liu H, Meng G, Li W, Gu T and Liu H (2019) Corrigendum: Microbiologically Influenced Corrosion of Carbon Steel Beneath a Deposit in $\mathrm{CO}_{2}$-saturated Formation Water Containing

Desulfotomaculum nigrificans. Front. Microbiol. 10:1653. doi: 10.3389/fmich.2019.01653

\section{Corrigendum: Microbiologically} Influenced Corrosion of Carbon Steel Beneath a Deposit in $\mathrm{CO}_{2}$-saturated Formation Water Containing Desulfotomaculum nigrificans

\author{
Hongwei Liu ${ }^{1 *}$, Guozhuo Meng ${ }^{1}$, Weihua $\mathrm{Li}^{1}$, Tingyue Gu ${ }^{2 *}$ and Hongfang Liu ${ }^{3 *}$ \\ ${ }^{1}$ School of Chemical Engineering and Technology, Sun Yat-sen University, Zhuhai, China, ${ }^{2}$ Department of Chemical and \\ Biomolecular Engineering, Institute for Corrosion and Multiphase Technology, Ohio University, Athens, OH, United States, \\ ${ }^{3}$ Key Laboratory of Material Chemistry for Energy Conversion and Storage, Ministry of Education, Hubei Key Laboratory of \\ Materials Chemistry and Service Failure, School of Chemistry and Chemical Engineering, Huazhong University of Science \& \\ Technology, Wuhan, China
}

Keywords: sulfate reducing bacteria, biofilm, carbon steel, under deposit corrosion, microbiological corrosion

\section{A Corrigendum on}

Microbiologically Influenced Corrosion of Carbon Steel Beneath a Deposit in $\mathrm{CO}_{2}$-saturated Formation Water Containing Desulfotomaculum nigrificans

by Liu, H., Meng, G., Li, W., Gu, T., and Liu, H. (2019). Front. Microbiol. 10:1298. doi: $10.3389 /$ fmicb.2019.01298

In the original article, there was a mistake in Figure $\mathbf{1 2}$ as published. Figures $12 \mathrm{~A}-\mathrm{H}$ are the same as Figures 13A-H. The correct Figure 12 appears below.

The authors apologize for this error and state that this does not change the scientific conclusions of the article in any way. The original article has been updated.

Copyright $\odot 2019 \mathrm{Liu}, \mathrm{Meng}, \mathrm{Li}$, Gu and Liu. This is an open-access article distributed under the terms of the Creative Commons Attribution License (CC BY). The use, distribution or reproduction in other forums is permitted, provided the original author(s) and the copyright owner(s) are credited and that the original publication in this journal is cited, in accordance with accepted academic practice. No use, distribution or reproduction is permitted which does not comply with these terms. 

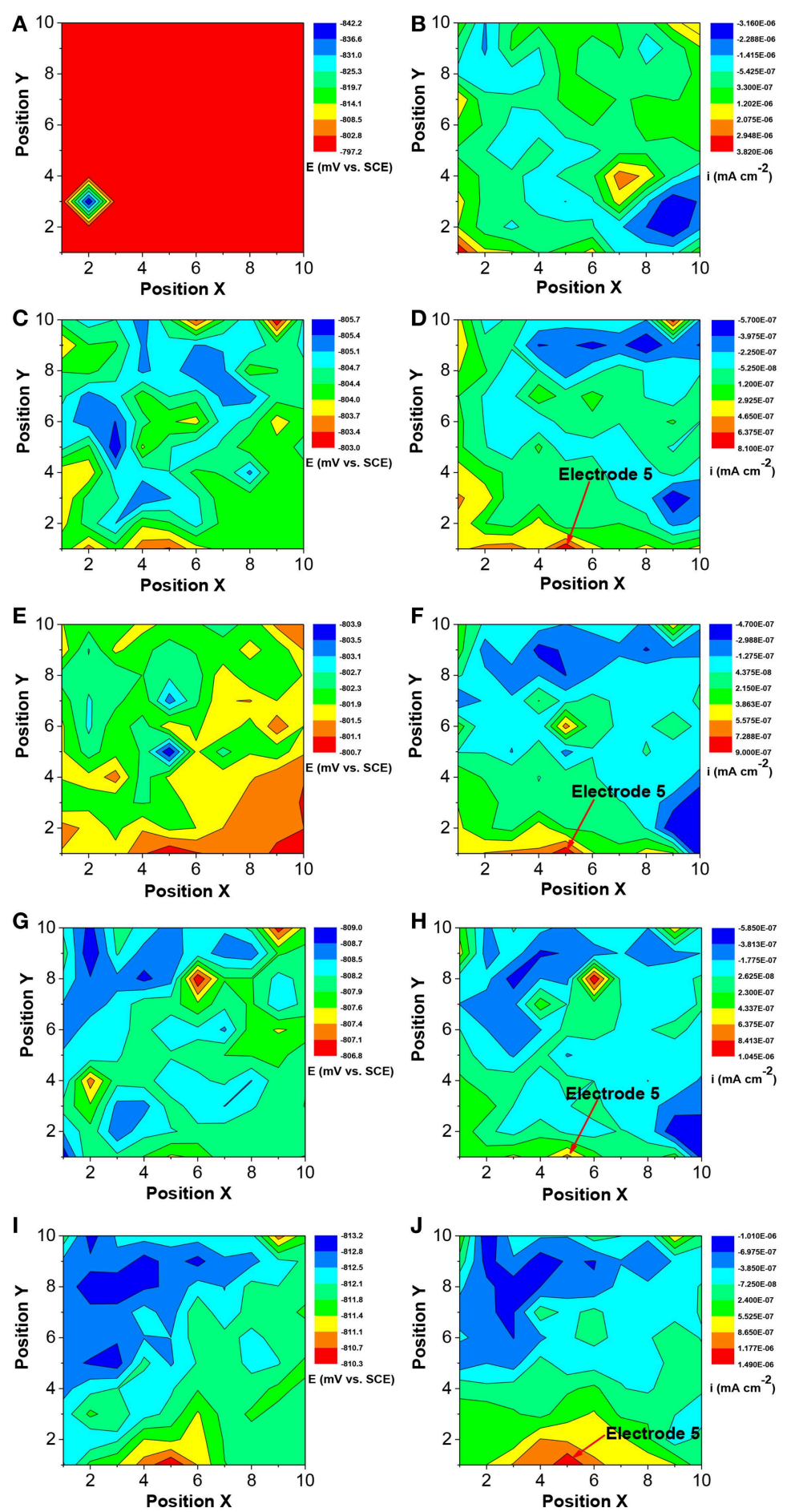

FIGURE 12 | Changes of corrosion potential (A,C,E,G,I) and galvanic current (B,D,F,H,J) distributions of Q235 WBE with incubation time in the absence of SRB in $\mathrm{CO}_{2}$-saturated simulated formation water: (A,B) 1 day; (C,D) 4 days; (E,F) 7 days; (G,H) 10 days and (E,F) 14 days. 